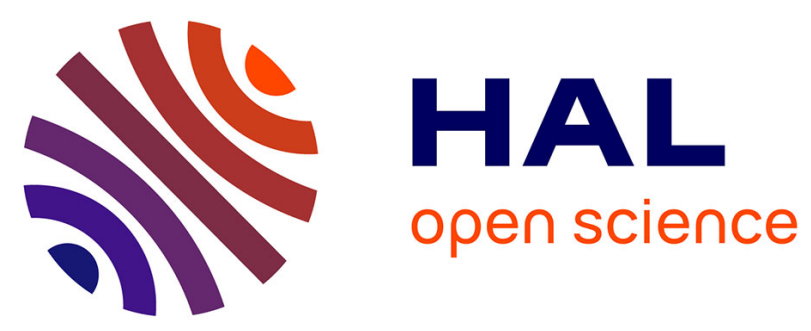

\title{
From Molecular Electrostatic Interactions and Hydrogel Architecture to Macroscopic Underwater Adherence
}

Francisco J. Cedano-Serrano, Ugo Sidoli, Alla Synytska, Yvette Tran, Dominique Hourdet, Creton Costantino

\section{- To cite this version:}

Francisco J. Cedano-Serrano, Ugo Sidoli, Alla Synytska, Yvette Tran, Dominique Hourdet, et al.. From Molecular Electrostatic Interactions and Hydrogel Architecture to Macroscopic Underwater Adherence. Macromolecules, 2019, 52 (10), pp.3852-3862. 10.1021/acs.macromol.8b02696 . hal02393203

\section{HAL Id: hal-02393203 \\ https://hal.science/hal-02393203}

Submitted on 4 Dec 2019

HAL is a multi-disciplinary open access archive for the deposit and dissemination of scientific research documents, whether they are published or not. The documents may come from teaching and research institutions in France or abroad, or from public or private research centers.
L'archive ouverte pluridisciplinaire HAL, est destinée au dépôt et à la diffusion de documents scientifiques de niveau recherche, publiés ou non, émanant des établissements d'enseignement et de recherche français ou étrangers, des laboratoires publics ou privés. 


\section{From Molecular Electrostatic Interactions and}

\section{Hydrogel Architecture to Macroscopic Underwater}

\section{Adherence}

Francisco J. Cedano-Serrano ${ }^{1}$, Ugo Sidoli $^{2,3}$, Alla Synytska ${ }^{2,3}$, Yvette Tran ${ }^{1}$, Dominique Hourdet ${ }^{1}$ and Costantino Creton $^{1} *$

${ }^{1}$ Soft Matter Sciences and Engineering, ESPCI Paris, PSL University, Sorbonne University, CNRS, F-75005 Paris, France.

${ }^{2}$ Department of Polymer Interfaces, Leibniz Institute of Polymer Research, Hohe Strasse 6, D01069 Dresden, Germany.

${ }^{3}$ Technische Universität Dresden, D-01062 Dresden, Germany 
ABSTRACT: We investigate the macroscopic adhesion energy $\left(W_{a}\right)$ in pure water between a positively charged hydrogel of varying crosslink density made from (methacryloyloxyethyl)trimethylammonium chloride and acrylamide [poly(MAETAC-co-AAm)] and a negatively charged and crosslinked poly(acrylic acid) (PAA) thin film gel grafted on a silicon wafer. Adhesion tests were carried out on a custom-built probe-tack setup fully immersed in pure water. The interfacial charge density on the PAA hydrogel thin film was estimated from streaming potential measurements and the molecular architecture of the thick hydrogel was obtained from mechanical testing. For a fixed interfacial charge density, $W_{a}$ increased weakly with contact time (in stark contrast with the case where adhesion is due to H-bonds) but strongly with debonding rate. For a given gel, the work of adhesion increased linearly with the interfacial charge density of the thin PAA film while at constant interfacial charge density, $W_{a}$ was found to decrease with the modulus of the gel. Results were analysed with a simple kinetic bond model proposed by Chaudhury for weak adhesion of elastomers. Using realistic values of the spring constant of the polymer chain and of the characteristic time of bond dissociation, we demonstrate that the work of adhesion can be understood by a combination of a strain rate dependent bond breaking kinetics and a $\mathrm{pH}$ dependent areal density of electrostatic interactions.

KEYWORDS: Electrostatic interactions, underwater adhesion, streaming potential, polyelectrolyte hydrogels, hydrogel thin films, Tack test. 


\section{INTRODUCTION}

Molecular electrostatic interactions play a key role in many macromolecular assemblies for bioadhesives systems. ${ }^{1}$ There is a growing interest in using ionic bonds for a broad range of applications in medicine, such as tissue engineering, ${ }^{2}$ drug delivery systems, ${ }^{3}$ and surgical adhesives ${ }^{4}$ because of their strength and tunability. For the latter application, adhesives systems using electrostatic interactions to achieve promising levels of adhesion for medical applications have been reported..$^{5}$ Yet, despite several previous studies, ${ }^{6-8}$ the control and quantitative prediction of macroscopic adhesion properties from molecular electrostatic interactions is still poorly understood for soft materials fully immersed in an aqueous environment.

Forces due to electrostatic interactions are well described by Coulomb's law in vacuum and molecular theories describing adhesion between charged molecules and surfaces, or in polymer science between polyelectrolytes, have been developed and verified experimentally. ${ }^{9}$ The presence of thin polymer films or polymer brushes on surfaces causes additional complexity related to the counterion condensation and local $\mathrm{pH}$ change. ${ }^{10,11}$ In addition macroscopic hydrogels are soft solids that can store elastic energy upon deformation, causing long range effects that in term affect macroscopic adhesive properties in a similar way than for classical soft elastomers where adherence is due to a balance between adhesive forces and strain energy. ${ }^{12}$ However for swollen hydrogels underwater, molecular forces and elastic strain energy are both much weaker and the coupling between molecular interactions causing short range attractive forces and gel mechanics is still poorly understood.

Initial investigations of this problem have measured the underwater adhesion energy at a nanometric force scale between oppositely charged polyelectrolyte brushes by using the AFMcolloidal probe technique. ${ }^{13-15}$ The main focus of this previous work was to achieve reversible 
adhesion by changing environmental variables such as $\mathrm{pH}^{6}$ or by adding salt. ${ }^{13}$ Additionally, repulsions resulting from electrostatic interactions have been extensively studied with the surface force apparatus. ${ }^{16-18}$. However, adhesion between molecules or monolayers focuses only on the molecular interactions but fails to consider the effect of the bulk mechanical properties of the tested materials. Recently, Geoghegan and coworkers ${ }^{6,8}$ reported underwater adhesion experiments between oppositely charged polymer brushes and macroscopic hydrogel hemispheres using the socalled Johnson-Kendall-Roberts (JKR) analysis. They focused on the reversibility and repeatability of the adhesive interactions but did not vary systematically charge density and hydrogel structure. Rose et al. ${ }^{19}$ obtained weak and reversible adhesion between highly swollen hydrogels by mediating the contact with nanoparticle able to adsorb on both surfaces with nonspecific interactions.

Our group has recently developed a novel methodology to measure the underwater adhesion energy $\left(W_{a}\right)$ between hydrogels and polymer brushes. ${ }^{20}$ The first objective was to obtain $\mathrm{pH}-$ responsive and reversible adhesion of a hydrogel on a hard surface. ${ }^{20}$ This technique was used to explore the effect of hydrogen bonding interactions on the $W_{a}$ between a poly(acrylic acid) brush and a poly(N,N-dimethylacrylamide) hydrogel, and a maximum $W_{a}$ of about $100 \mathrm{~mJ} / \mathrm{m}^{2}$ was reported. This methodology was also used to measure $W_{a}$ as the poly(N,N-dimethyl acrylamide) hydrogel swollen from its preparation state until equilibrium. ${ }^{21}$ This study showed that adhesion always decreases as the gels equilibrate with their surroundings regardless of the initial hydrogel polymer concentration and degree of crosslinking. In this article, we investigate the adhesion between negatively charged surfaces and positively charged highly elastic hydrogels. Because our gels are well crosslinked we expect to minimize viscoelastic dissipation and maximize the sensitivity of the adhesion test to the specific interfacial interactions. 
Due to the electrostatic nature of this adhesive system, we propose the use of electrokinetic measurements (i.e. streaming potential or streaming current) to estimate the surface density of electric charges at the surface of the hydrogel thin film. Descriptions of the charge distribution at the interface are based on the electric double layer model developed by Gouy and Chapman and completed by Stern and Grahame (GSCG model). ${ }^{22,23}$ The GSCG model describes the charging processes taking place at a solid/liquid interface by introducing two parallel layers of charge surrounding a solid surface, a fixed layer called stern layer and a mobile layer called diffuse layer. Between these two layers lies a "slip plane" and the potential of this plane is the zeta potential $(\zeta)$. From this $\zeta$ value it is possible to estimate the charge density at the top of a solid surface and, therefore, to estimate the interfacial charge density for our system. It is expected that $W_{a}$ should increase with increasing charge density at the interface, since more interactions will be formed, which in turn should increase the stress needed to break this interface.

Additionally, since the adhesion energy is the energy necessary to separate two surfaces, it may also contain an irreversible component, which in turn depends on the bulk mechanical properties of the macroscopic hydrogel. This is predicted by fracture models, such as the Lake and Thomas model, ${ }^{24}$ where the energy to break a soft material is predicted to scale with the inverse square root of the elastic modulus. ${ }^{25}$ In other words the irreversible contribution to $W_{a}$ is expected to increase as the elastic modulus of the gels decreases. However, the Lake-Thomas model is not suitable to study adhesion of our system since it assumes that bond scission and hence the fracture energy, are rate independent, and previous work ${ }^{8,20}$ on hydrogel/brush adhesion suggests that the adhesion energy is likely to be debonding rate dependent. Chaudhury ${ }^{26}$ proposed a weak adhesion model in which the fracture energy of an interface is rate-dependent due to the rate dependent nature of the scission of individual bonds at the interface according to the description of Evans et al. ${ }^{27,28}$ The 
adhesion energy can then be estimated as a function of kinetic parameters of bond scission and the polymer strand in the hydrogel is seen as a linear spring with a spring constant that is inversely proportional to the length of the chain. This in turn predicts that the adhesion energy should be directly related to the bulk mechanical properties of the macroscopic hydrogel, and in particular to its mesh size.

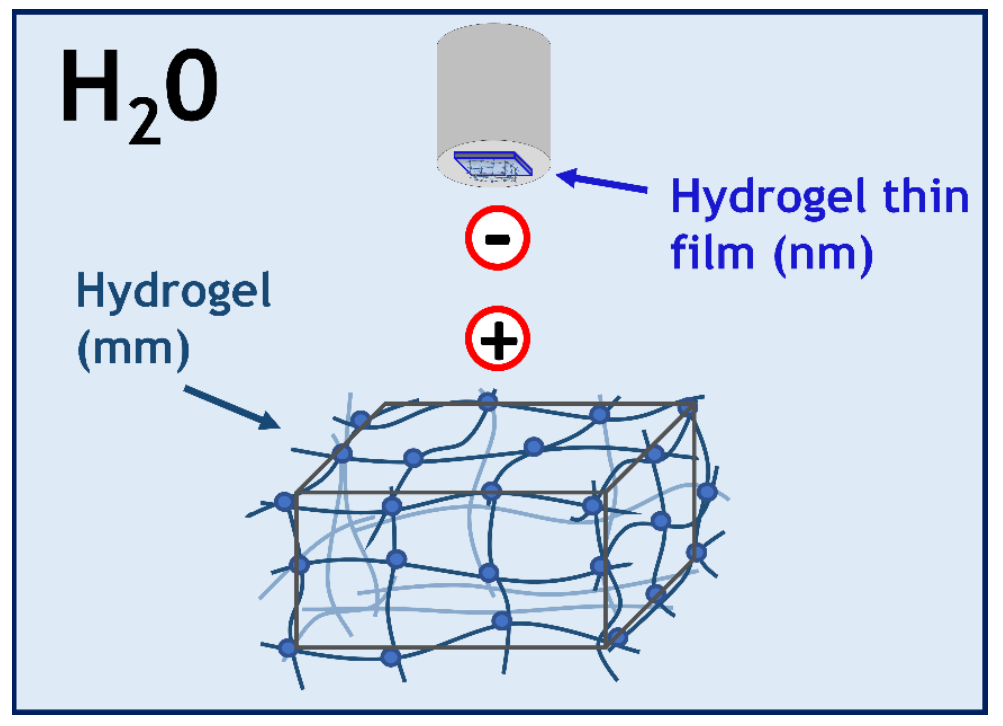

Figure 1. Simplified scheme of a tack test underwater between a hydrogel (Thickness $<2 \mathrm{~mm}$ ) positively charged and a hydrogel thin film (Thickness $<0.5 \mu \mathrm{m}$ ) negatively charged.

In this work, model polyelectrolyte hydrogels were selected to measure $W_{a}$ between a positively charged hydrogel and a negatively charged hydrogel thin film (Figure 1). Specifically, we investigated the effect of the hydrogel network architecture and of the interfacial charge density on $W_{a}$ with the intention of bridging the gap between a specific molecular interaction and the macroscopic underwater adherence energy. 


\section{EXPERIMENTAL}

\subsection{Chemicals}

All chemicals were used as received from the supplier. For the macroscopic hydrogels, 2(methacryloyloxy)ethyltrimethylammonium chloride 80 wt. \% in $\mathrm{H}_{2} \mathrm{O}$ (MAETAC), acrylamide for electrophoresis, $\geq 99 \%$ (AAm), N,N'-methylenebisacrylamide (MBA), potassium persulfate (KPS) and tetramethylethylenediamine (TEMED) were purchased from Sigma-Aldrich, France.

For the synthesis of hydrogel thin films, allylamine, 1-ethyl-3-(3dimethylaminopropyl)carbodiimide hydrochloride (EDC), N-hydroxysulfosuccinimide (NHS), 1,4-dithioerythritol, toluene dried $\left(\max .0 .005 \% \mathrm{H}_{2} \mathrm{O}\right)$, formic acid and methanol were all purchased from Sigma-Aldrich, France. Additionally, poly(acrylic acid) (PAA with $\mathrm{M}_{\mathrm{W}} \sim 50$ $\mathrm{kg} / \mathrm{mol}, 25 \mathrm{wt} \%$ in water was obtained from Polysciences. (3-Mercaptopropyl)trimethoxysilane was obtained from Alfa chemistry. Silicon wafers were purchased from Applications Couches Minces ACM, France.

\subsection{Hydrogel synthesis}

A series of positively charged hydrogels was prepared by free radical copolymerization in water using a cationic monomer (MAETAC), a neutral comonomer (AAm) and a tetrafunctional crosslinker (MBA). Within this series, the total monomer concentration was fixed at $20 \mathrm{wt} \%(80$ $\mathrm{wt} \%$ in water $)$, using two different MAETAC/AAm molar ratios $(10 / 90=\mathrm{I} 10$ and 20/80 $=\mathrm{I} 20)$ and 3 different molar percentages of crosslinker $(\mathrm{R}=1,2$ and $4 \mathrm{~mol} \%$ with respect to total monomers).

After dissolution at room temperature of the comonomers in Milli-Q water ( $\mathrm{pH} 5.5$ ), the KPS initiator was added ( $1 \mathrm{~mol} \%$ relative to the total monomer) and the solution was deoxygenated 
under $\mathrm{N}_{2}$ flow during $30 \mathrm{~min}$. Then, as soon as the reducing agent TEMED was added ( $1 \mathrm{~mol} \%$ as KPS), the solution was transferred to a PDMS mold of $0.1 \mathrm{~cm} \times 2 \mathrm{~cm} \times 4 \mathrm{~cm}$ size. The redox initiation rapidly took place and the polymerization was left to proceed overnight under nitrogen atmosphere. The mold was then opened, and the $1 \mathrm{~mm}$ thick gels were immersed and stored in 1 L of Milli-Q water until final use.

The poly(MAETAC-co-AAm) hydrogels prepared in this way will be called Ix-Ry, with $\mathrm{x}=10$ or 20 the molar percentage of ionic comonomer and $\mathrm{y}=1,2$ or $4 \mathrm{~mol} \%$ the molar percentage of crosslinker with respect to the monomers.

For equilibrium swelling studies, hydrogels were initially weighted in their preparation state $\left(m_{p}\right)$ before immersion into a large volume of Milli-Q water. After 3 days of equilibrium with water renewal, the swollen samples were weighted again $\left(m_{s}\right)$ and then dried overnight in an oven (at $60{ }^{\circ} \mathrm{C}$ ) in order to get their final dry weight $\left(m_{d}\right)$. These measurements allow calculating the mass swelling ratio at equilibrium $\left(\Lambda_{e}=m_{s} / m_{d}\right)$, as well as to estimate the volume swelling ratio at preparation state according to the following equation

$$
Q_{0}=1+\frac{v_{w}}{v_{p}}\left(\frac{m_{p}}{m_{d}}-1\right)
$$

where $v_{w}=1.00 \mathrm{~cm}^{3} \cdot \mathrm{g}^{-1}$ is the specific volume of water and $v_{p}$ is the specific volume of the comonomer. $v_{p}=0.76 \mathrm{~cm}^{3} \cdot \mathrm{g}^{-1}$ for I10 and $v_{p}=0.774 \mathrm{~cm}^{3} \cdot \mathrm{g}^{-1}$ for I 20 .

\subsection{Synthesis of negatively charged hydrogel thin films}

Surface-attached thin hydrogel films were prepared by simultaneously crosslinking and grafting pre-functionalized poly(acrylic acid) (PAA) onto thiol-modified silicon wafers. The crosslinking and grafting took place through a thiol-ene click reaction following a previously published procedure, which will be briefly described in the following paragraphs. ${ }^{29,30}$ 
Functionalization of poly(acrylic acid) with double bonds

Poly(acrylic acid) (PAA) chains were randomly functionalized with ene-groups at their carboxylic acid sites. A peptide reaction was used to graft allylamine onto polymer chains in the presence of EDC and NHS. ${ }^{31}$ Briefly, a $20 \mathrm{wt} \%$ solution of PAA in Milli-Q water was mixed with EDC and NHS at a pH of 4.5 for $2 \mathrm{~h}$. Allylamine was then added and the $\mathrm{pH}$ was adjusted to 10 before the reaction was allowed to proceed for $16 \mathrm{~h}$. Finally, the polymer was recovered through freeze-drying after 2 days of dialysis in $0.1 \mathrm{M} \mathrm{NaCl}$ solution and 3 days of dialysis in Milli-Q water. The ene-functionalization of PAA was confirmed by Proton Nuclear Magnetic Resonance $\left({ }^{1} \mathrm{H}\right.$ NMR) spectroscopy performed in deuterated water with a $400 \mathrm{MHz}$ Bruker spectrometer. ${ }^{1} \mathrm{H}$ NMR spectrum of PAA ene-functionalized is provided in supporting information (Figure S2).

\section{Thiol-modification of Substrates}

Silanization of the silicon wafers with thiolfunctional alkoxysilane was carried out as follows. After irradiation by UV-ozone for $15 \mathrm{~min}$, the wafers were transferred into a sealed reactor under $\mathrm{N}_{2}$ atmosphere. A solution of dry toluene with $3 \mathrm{vol} \%$ of mercaptopropyltrimethoxysilane was introduced into the reactor using a cannula. The wafers were kept immersed in the solution for 3 $\mathrm{h}$ inside the reactor always in $\mathrm{N}_{2}$. The samples were then rinsed and sonicated in toluene for $1 \mathrm{~min}$ and finally dried with nitrogen flow.

\section{Synthesis of PAA Hydrogel Thin Films}

A thin layer of PAA functionalized with ene-groups was deposited on the thiol-modified wafers by spin-coating from a $2 \mathrm{wt} \%$ solution in methanol and formic acid $(70 \%$ methanol and $30 \%$ formic 
acid) containing also dithioerythritol. The ratio of dithioerythritol to ene-functionalized polymer units was 15 , corresponding to a molar ratio of 30 between $-\mathrm{SH}$ groups of the bifunctional dithioerythritol and double bonds. The thickness of the resultant films depends on various factors but mainly on the concentration of the polymer for spin-coating and on its molecular weight. ${ }^{29}$ The conditions of spin-coating were fixed with a final angular velocity of $3000 \mathrm{rpm}$ and a spinning time of $15 \mathrm{~s}$. After spin coating, the dry films were annealed at $120^{\circ} \mathrm{C}$ for $24 \mathrm{~h}$ under vacuum to activate the thiol-ene reaction. Finally, the wafers were cleaned with water and then cleaved into pieces of $5 \mathrm{~mm} \times 5 \mathrm{~mm}$. Ellipsometry measurements were used to corroborate that the thiol-ene reaction effectively took place and that PAA thin films were grafted to the silicon wafer.

\subsection{Characterization of the elastic properties of the bulk hydrogels}

Cylindrical samples ( $8 \mathrm{~mm}$ diameter, $12 \mathrm{~mm}$ height) were prepared in a silicone mold and tested $24 \mathrm{~h}$ after the polymerization, to estimate the shear modulus in the preparation state $\left(G_{0}\right)$, and at swelling equilibrium $\left(G_{e}\right)$. Compression tests were carried out using a custom-built setup with a uniaxial testing machine (Instron, model 3343) and a $10 \mathrm{~N}$ load cell. Each sample was preloaded with a compression force of $50 \mathrm{mN}$ followed by a compressive loading at a constant displacement rate of $50 \mu \mathrm{m} / \mathrm{s}$ until a maximum load of $5 \mathrm{~N}$ was achieved. Before the test, all specimens were coated with paraffin oil to avoid friction forces between hydrogels and the testing plates during the uniaxial compression. The compressive modulus $(E)$ was calculated as the slope of the linear regression line for data between $5 \%$ and $15 \%$ of strain. Assuming that hydrogels are incompressible for these relatively high rates relative to their geometry (Poisson's ratio $=0.5$ ), the shear modulus $(\mathrm{G})$ was estimated as 


$$
G=\frac{E}{3}
$$

The molecular weight between crosslinks $\left(M_{C}\right)$ of poly(MAETAC-co-AAm) hydrogels can be determined from the shear modulus of the samples in their preparation state $\left(G_{0}\right)$. Here we use the phantom network model which assume that the junction points can freely move and fluctuate over time on a range which is not affected by the macroscopic deformation. ${ }^{32}$ According to this model $M_{C}$ can be determined from the following expression:

$$
G_{0}=\left(1-\frac{2}{f}\right) \frac{R T}{v_{p} M_{C}} \frac{1}{Q_{0}}
$$

where $\mathrm{R}$ is the gas constant, $\mathrm{T}$ the temperature, $f$ is the functionality of the crosslinker $(f=4$ for MBA), and $Q_{0}$ is the initial volume swelling ratio. The number of monomers in the chain between crosslinks $\left(N_{c}\right)$ is calculated as $M_{C}$ divided by the average molar mass per repeat unit $\left(M_{0}\right)$, which depends on the cationic monomer molar percentage $(I)$ as follows

$$
N_{c}=\frac{100 * M_{c}}{I * M_{M A E T A C}+(100-I) * M_{A A m}}
$$

where $M_{\text {MAETAC }}$ and $M_{A A m}$ are the molar masses of MAETAC and AAm respectively.

\subsection{Characterization of the hydrogel thin films}

The thickness of the PAA films in air $\left(h_{a}\right)$ and underwater $\left(h_{w}\right)$ were measured using a spectroscopic ellipsometer (UVISEL, Horiba) with a wavelength range from $260 \mathrm{~nm}$ to $850 \mathrm{~nm}$ (in air) and from 320 to $850 \mathrm{~nm}$ (underwater). The refractive index $\left(n_{i}\right)$ of the silicon wafer is 3.875. A model with two layers was used for measurements in air. The first layer comprises silica and silane $\left(n_{i}=1.46\right)$ the thickness of which was determined before grafting the hydrogel film (between 2 and $3 \mathrm{~nm}$ ). The second layer was the PAA hydrogel film $\left(n_{i}=1.50\right)$. Underwater 
measurements were performed with a controlled temperature liquid cell equipped with thin glass walls (fixed perpendicularly to the light path with the angle of incidence at $60^{\circ}$ ). The polymer hydrogel film was modelled as a single layer $\left(h_{w}\right)$ with a constant refractive index between that of water $\left(n_{i}=1.33\right)$ and of the polymer. The swelling ratio of hydrogel films $\left(\Lambda_{f}\right)$ was calculated as $h_{w} / h_{a}$, assuming that the amount of polymer is the same when immersed in water, since it is chemically grafted to the substrate. ${ }^{30}$ The thickness was measured for samples fully immersed in Milli-Q water at $\mathrm{pH}$ of 2, 4, 5.5 and 8. Two replicas were performed for each test environment.

\subsection{Streaming Potential Measurements on Charged Surfaces}

Electrokinetic measurements are a versatile tool for investigating charge formation at interfaces between polymers and aqueous solutions. ${ }^{22,33}$ By using the GSGC model described before, it is possible to relate the measured electrokinetic quantity (i.e. streaming potential or streaming current) with the degree of dissociation and the interfacial charge density of the PAA thin films. In this project, the surface potentials of the PAA thin films were determined by streaming potential measurements using an Electrokinetic Analyzer (EKA) (Anton Paar GmbH, Austria).

For the streaming potential measurements, two pieces of silicon wafers (10 $\mathrm{mm} \times 20 \mathrm{~mm}$ each) grafted with PAA (dry thickness: $30 \mathrm{~nm}$ ) were attached to the rectangular cell with adhesive tape so that they were facing each other and formed a streaming channel where the measuring fluid flows through. During the experiment, the pressure inside the fluid channel $(p)$ was continuously varied and the streaming potential at zero net current conditions $(U)$ was measured for each value of $p$. The zeta potential $\zeta$ was then calculated using the expression developed by Smoluchowski ${ }^{34}$

$$
\zeta=\frac{d U}{d p} \frac{\eta}{\varepsilon_{r} \varepsilon_{0}} k
$$


where $\varepsilon_{0}$ is the vacuum permittivity constant $\left(8,85 \times 10^{-12} \mathrm{~F} / \mathrm{m}\right) . \varepsilon_{r}, \eta$ and $k$ are the dielectric constant, viscosity and the specific conductivity of the measuring fluid respectively. These last 3 variables are measured independently for each specific $\mathrm{pH}$. The $\mathrm{pH}$-dependence of the zeta potential $(\zeta)$ for PAA thins films was determined in a $\mathrm{KCl}$ solution $(1 \mathrm{mM})$ for a $\mathrm{pH}$ range from 2.5 to 10.5 . Measurements started at $\mathrm{pH} \sim 6$ followed by stepwise addition of $\mathrm{HCl}$ or $\mathrm{KOH}(0.1$ M) to sweep between more acidic and more basic $\mathrm{pH}$ values, respectively. One pair of PAA films was used for the acidic environment and a different pair was used for the basic environment. Four measurements were conducted at each specific $\mathrm{pH}$.

\subsection{Underwater Tack Test}

The underwater tack test was conducted on an experimental setup designed by Sudre et al..$^{20}$ The effect of several parameters of the test have been investigated for hydrogels at equilibrium ${ }^{20}$ and for non-swollen hydrogels. ${ }^{21}$ In this publication, all hydrogels were tested after reaching swelling equilibrium in Milli-Q water.

Briefly, the adhesion test consisted in forming a parallel contact and detachment between a macroscopic positively charged hydrogel (thickness $\sim \mathrm{mm}$ ) and a negatively charged thin hydrogel film (thickness $\sim$ nm) while both were fully immersed in an aqueous environment. The $5 \mathrm{~mm}$ x 5 mm wafer coated with the surface-grafted PAA hydrogel thin film was glued with a polyvinyl acetate adhesive (ref. L0196, 3M®, France) to a stainless-steel probe, which was fixed to a $10 \mathrm{~N}$ load cell and connected to a universal tensile machine (model 5333, Instron ${ }^{\circledR}$, France). A sample of poly(MAETAC-co-AAm) hydrogel (20 mm x $20 \mathrm{~mm}$ x $1 \mathrm{~mm}$ ) was glued to a glass microscope slide with a cyanoacrylate adhesive (Loctite ${ }^{\circledR} 495$, France). The test requires a parallel contact between both surfaces to be aligned during the test. The alignment is performed in air and is 
considered as successful when the time to bring both surfaces into contact is less than 5 seconds for an approaching speed of $10 \mu \mathrm{m} / \mathrm{s}$ until a pressure of $3 \mathrm{kPa}^{21}$ Additionally, the thin film is protected with a stretched layer of Parafilm ${ }^{\circledR}$ during the alignment in air. If the thin film is not protected, it is likely that the macroscopic hydrogel will break and damage the thin film surface.

After this alignment, the contact was made underwater at an approaching rate of $10 \mu \mathrm{m} / \mathrm{s}$ with a contact area determined by the surface of the silicon wafer functionalized by the PAA thin film. A preload of $3 \mathrm{kPa}$ was applied for a given constant contact time that was varied from $1 \mathrm{~s}$ to 1200 s. Finally, the probe was detached at a constant debonding rate $\left(\mathrm{V}_{\mathrm{deb}}\right)$ while recording the probe displacement and the force. From this experiment, the work of adhesion $W_{a}$ can be calculated as follows:

$$
W_{a}=T_{0} \int_{0}^{\varepsilon_{\max }} \sigma d \varepsilon
$$

where $\varepsilon$ is the nominal strain and is obtained by normalizing the displacement by the initial thickness of the thick hydrogel $\left(T_{0}\right) . \sigma$ is the average stress and is obtained by dividing the force by the contact area. Three replicates were conducted for each experiment.

\section{RESULTS}

\subsection{Elastic moduli of the Bulk Hydrogels}

A series of poly(MAETAC-co-AAm) hydrogels were synthesized to study the impact of the network architecture on the underwater adhesion properties. Swelling studies and mechanical characterization were conducted on each prepared hydrogel (Table 1). Increasing the molar ratio of crosslinker from 1 to $4 \mathrm{~mol} \%$ caused the equilibrium degree of swelling $\left(\Lambda_{\mathrm{e}}\right)$ to decrease by nearly $30 \%$ and $50 \%$ for I10 and for I20, respectively. Additionally, the average molecular weight $\left(M_{C}\right)$ and number of monomers between crosslinks $\left(N_{c}\right)$ decreased by about $50 \%$ for both I10 and 
I20 by doubling the crosslinking molar concentration, as expected from hydrogel network models, where $M_{C}$ is inversely proportional to the degree of crosslinking of the hydrogel and that properties are controlled by chemical crosslinks rather than entanglements. ${ }^{35}$

\begin{tabular}{|c|c|c|c|c|c|c|c|}
\hline Hydrogel & $Q_{0}$ & $\mathrm{C}_{\mathrm{e}}(\mathrm{wt} \%)$ & $\Lambda_{\mathrm{e}}$ & $\mathrm{E}_{0}(\mathrm{kPa})$ & $\mathrm{E}_{\mathrm{e}}(\mathrm{kPa})$ & $M_{C}(\mathrm{~kg} / \mathrm{mol})$ & $N_{c}$ \\
\hline I10-R1 & 6.3 & 4.9 & 21.1 & $123 \pm 18$ & $99.6 \pm 20.1$ & 6.35 & 75 \\
\hline I10-R2 & 6.3 & 10.2 & 9.8 & $232 \pm 8.4$ & $207 \pm 18.9$ & 3.37 & 40 \\
\hline I10-R4 & 6.3 & 15.7 & 6.4 & $433 \pm 6.9$ & $456 \pm 74.4$ & 1.80 & 21 \\
\hline I20-R1 & 6.2 & 3.9 & 26.8 & $98.4 \pm 3.9$ & $70.8 \pm 6.3$ & 7.93 & 81 \\
\hline I20-R2 & 6.2 & 5.7 & 17.6 & $256 \pm 6.0$ & $199 \pm 14.7$ & 3.05 & 31 \\
\hline I20-R4 & 6.2 & 7.7 & 13 & $372 \pm 16.8$ & $332 \pm 88.2$ & 2.10 & 21 \\
\hline
\end{tabular}

Table 1. Composition and characteristics of cationic hydrogels. Initial volume swelling $\left(Q_{0}\right)$, total polymer concentration at swelling equilibrium $\left(\mathrm{C}_{\mathrm{e}}\right)$, mass degree of swelling at equilibrium $\left(\Lambda_{\mathrm{e}}\right)$, Young's modulus in the preparation conditions $\left(\mathrm{E}_{0}\right)$ and at swelling equilibrium $\left(\mathrm{E}_{\mathrm{e}}\right)$. Both moduli are presented as average \pm standard deviation. Average molecular weight between crosslinks $\left(M_{C}\right)$ obtained from the shear modulus in preparation conditions and average number of monomers between crosslinks $\left(N_{c}\right)$.

The mechanical characterization of poly(MAETAC-co-AAm) hydrogels was carried out in compression (Figure 2.a). Representative curves, for I10-R2 and I10-R4 hydrogels at equilibrium show that the linearity of loading and unloading follows the same trajectory with a strain offset of $0.5 \% \pm 0.05 \%$ at zero stress. This suggests that there is not much energy dissipation and that these hydrogels are very elastic at a strain less than $20 \%$. The objective being to maximize the sensitivity to interfacial interactions relative to bulk dissipative mechanisms. Moreover, $\mathrm{E}_{0}$ and $\mathrm{E}_{\mathrm{e}}$ increased linearly from approximately $100 \mathrm{kPa}$ to $400 \mathrm{kPa}$ for both I10 and I20 when the molar ratio of crosslinker was increased from $1 \mathrm{~mol} \%$ to $4 \mathrm{~mol} \%$ (Figure 2.b). 
(a)

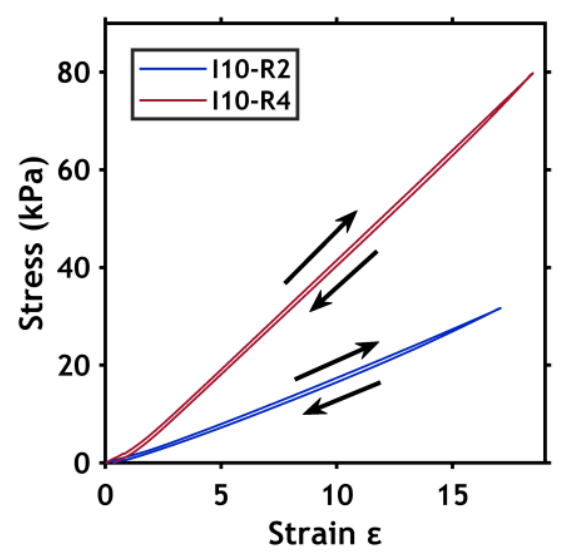

(b)

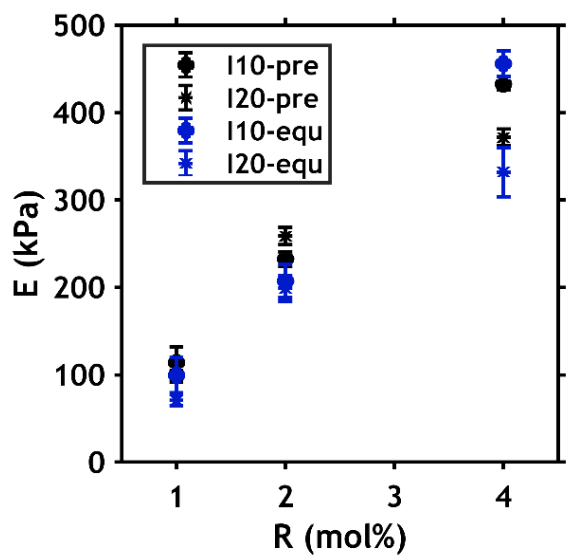

Figure 2. (a) Example of compression stress-strain curves for I10-R2 and I10-R4 hydrogels. Black arrows show loading direction. (b) I10 and I20 poly(MAETAC-co-AAm) hydrogel elastic modulus in the preparation state $\mathrm{E}_{0}$ (black symbols) and at equilibrium state $\mathrm{E}_{\mathrm{e}}$ (blue symbols) as a function of $\mathrm{R}$.

\subsection{Thickness and water content of negatively charged hydrogel thin films}

We used a technique previously developed for coating polymer films with dry thicknesses ranging roughly from 20 to $600 \mathrm{~nm} .{ }^{29,30,36}$ These polymer films are insoluble in water as the PAA chains are covalently crosslinked and chemically grafted to the silica wafers. Ellipsometry measurements show that their dry thickness remains constant and therefore, not damaged by underwater adhesion tests. A solution of PAA at $2 \mathrm{wt} \%$ leads to samples of thin films with a dry thickness of $144 \mathrm{~nm}$. Only PAA solutions at this concentration were used for all the experiments in this article. The underwater thickness of these PAA films increased to around $200 \pm 1.4 \mathrm{~nm}$ at $\mathrm{pH} 2$ corresponding to a swelling ratio of 1.4. By increasing the $\mathrm{pH}$, the progressive ionization of $\mathrm{COOH}$ groups and the increasing concentration of counterions are responsible for an additional 
osmotic pressure within the thin gel that leads to higher swelling of the film from 1.4 at $\mathrm{pH} 2$ and up to 1.8 at $\mathrm{pH} 8$ (Table 2$)$.

\begin{tabular}{|c|c|c|}
\hline & $\boldsymbol{h}_{\boldsymbol{w}}(\mathrm{nm})$ & $\Lambda_{e}$ \\
\hline $\mathrm{pH} 2.0$ & $200 \pm 1.4$ & 1.39 \\
\hline $\mathrm{pH} 4.0$ & $238 \pm 3.8$ & 1.65 \\
\hline $\mathrm{pH} 5.5$ & $252 \pm 1.2$ & 1.75 \\
\hline $\mathrm{pH} 8.0$ & $257 \pm 8.5$ & 1.78 \\
\hline
\end{tabular}

Table 2. Ellipsometry measurements of the thickness of PAA films underwater $\left(h_{w}\right)$ at different $\mathrm{pH}$ (average \pm standard deviation). Average swelling ratio of $\mathrm{PAA}$ films $\left(\Lambda_{e}\right) .2$ replicas were conducted for each sample.

\subsection{Adhesive properties}

Effect of experimental conditions: Contact time and debonding rate

Using the same adhesion measurement technique and geometry, previous work has shown that underwater adhesion based on H-bonds interactions depends markedly on contact time as it is necessary to maintain a contact time long enough ( $>2 \mathrm{~min}$ ) for the interactions to form at the interface and to reach values of $W_{a}$ of around $100 \mathrm{~mJ} / \mathrm{m}^{2} .{ }^{20}$ However, we observe a different behaviour for electrostatic interactions. At two different debonding rates $(0.1$ and $0.01 \mathrm{~mm} / \mathrm{s})$, the $W_{a}$ slightly increased and only by a factor of two between 1 second and 1200 seconds (Figure 3.a, 3.c and 3.d). This suggests that most of the electrostatic interactions at the interface are formed as soon as both surfaces come into contact and the surface density of interactions remains relatively constant thereafter. A contact time of 1 second is therefore enough in this case to achieve an adhesion energy of $\sim 600 \mathrm{~mJ} / \mathrm{m}^{2}$ at $\mathrm{V}_{\text {deb }}=0.1 \mathrm{~mm} / \mathrm{s}$ and $\sim 150 \mathrm{~mJ} / \mathrm{m}^{2}$ at $\mathrm{V}_{\text {deb }}=0.01 \mathrm{~mm} / \mathrm{s}$. These 
values are two orders of magnitude superior to that obtained with H-bonds interactions for the same contact time and same $\mathrm{V}_{\text {deb. }}{ }^{20}$

(a)

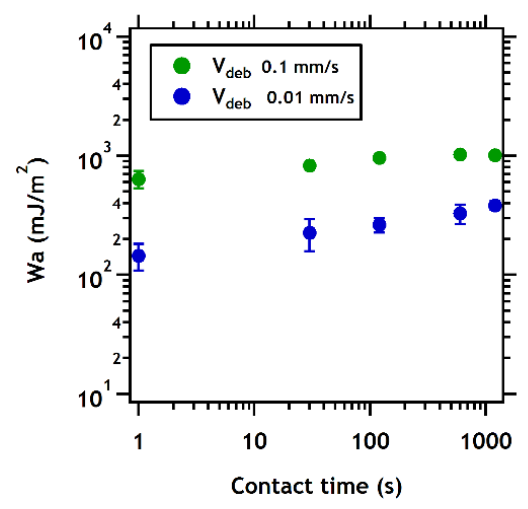

(c)

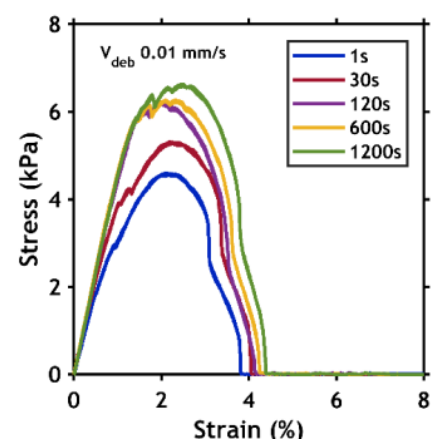

(e)

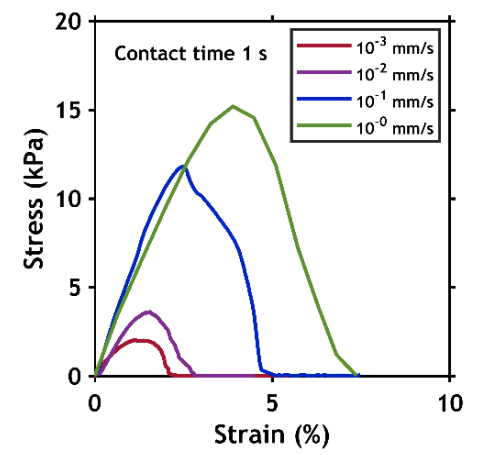

(b)

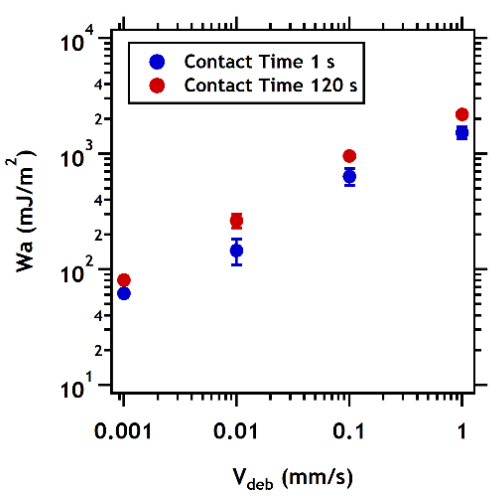

(d)

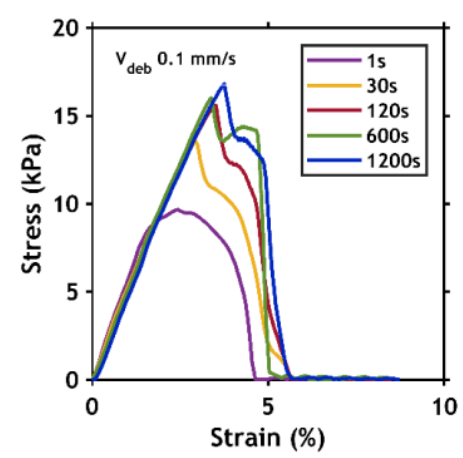

(f)

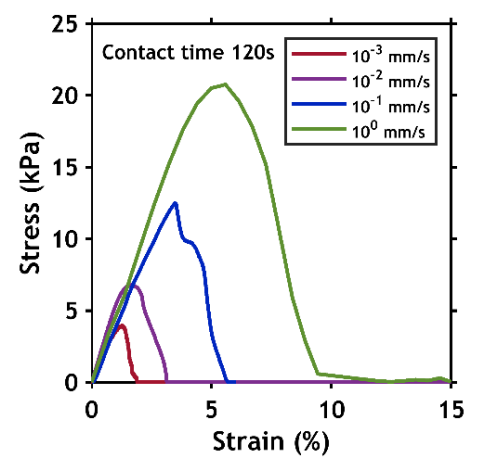

Figure 3. Variation of the adhesion energy measured in Milli-Q water ( $\mathrm{pH} 5.5$ ) between poly(MAETAC-co-AAm) hydrogel (I10-R2) and PAA hydrogel thin film (dry thickness of 150 $\mathrm{nm}$ ) as a function of contact time (a) and $\mathrm{V}_{\mathrm{deb}}(\mathrm{b})$. The impact of these two parameters on the 
adhesion energy $\left(W_{a}\right)$ are detailed with stress-strain curves which have been plotted as a function of contact time at a given debonding rate, of $0.01 \mathrm{~mm} / \mathrm{s}(\mathrm{c})$, and $0.1 \mathrm{~mm} / \mathrm{s}(\mathrm{d})$ or as a function of debonding rate at a fixed contact time of 1 second (e) or 120 seconds (f).

In addition to the contact time, the debonding rate may play an important role on $W_{a}$. In classical soft adhesive systems, the influence of the velocity is linked to the bulk dissipative effects that are essential for the usual viscoelastic hydrophobic adhesives, ${ }^{25}$ while at lower velocities only the thermodynamic work of adhesion is measured. However, in the framework of our study, the hydrogels are highly elastic materials, as shown by the compression tests, and the bulk dissipative effects are therefore negligible. Nevertheless, Figures 3.b., 3.e and 3.f show for two different contact times that $W_{a}$ increases by two orders of magnitude (from $\sim 10 \mathrm{~mJ} / \mathrm{m}^{2}$ to $\sim 1000 \mathrm{~mJ} / \mathrm{m}^{2}$ ) as the debonding rate increases by four orders of magnitude (from $0.1 \mu \mathrm{m} / \mathrm{s}$ to $1 \mathrm{~mm} / \mathrm{s}$ ).

\section{Materials Effects: Effect of the Crosslinking Density $R$ of the Hydrogel on $W_{a}$}

Probe tack tests are used to measure the energy required to separate the negatively charged surface from the positively charged hydrogel without breaking any covalent bonds within either of the hydrogels. For this reason, $W_{a}$ between each hydrogel and thin film was first measured as a function of different repetitions in the same spot. In Figure 4, Blue and Green lines show examples of probe-tack tests where $W_{a}$ remained constant for five consecutive contacts in the same spot, and in this case the value of $W_{a}$ in the first contact was used. In contrast, the red line shows an example where $W_{a}$ is not constant during different repetitions and since this strongly suggested that covalent bonds were broken in one of the hydrogels, the result were then not used for the study, Further examples, including stress-strain curves are shown in Figure S3. 


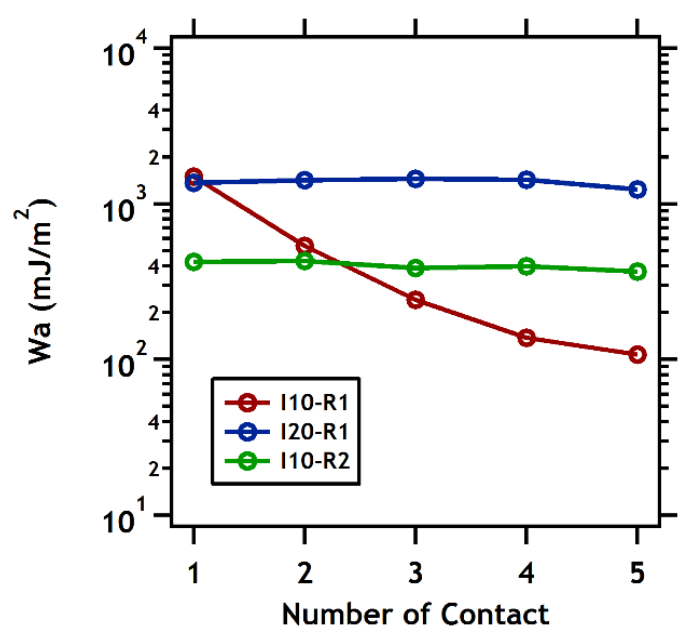

Figure 4. Adhesion energy results of the poly(MAETAC-co-AAm) hydrogels and the PAA hydrogel thin film (with dry thickness of $150 \mathrm{~nm}$ ) as function of number of contacts. Corresponding stress-strain curves are shown in Figure S3.

The impact of the hydrogel bulk mechanical properties on $W_{a}$ was studied by varying the degree of crosslinking $R$ and the molar ionic content $I$ in the hydrogel while measuring its adhesive properties against the same PAA hydrogel thin film. The hydrogels were kept in Milli-Q water until they reached swelling equilibrium. Afterwards adhesion tests were conducted in the same environment with a contact time of 1 second and a debonding rate of $0.1 \mathrm{~mm} / \mathrm{s}$. Three replicates were done for each experiment where both the hydrogel sample and the PAA thin film were used only once.

The adhesion energy measured as a function of R for I10 and I20 (Figure 5.a) shows that $W_{a}$ decreased by a factor of 10 regardless of the amount of cationic monomer units for increasing degree of crosslinking between $1 \mathrm{~mol} \%\left(\sim 1200 \mathrm{~mJ} / \mathrm{m}^{2}\right)$ and $4 \mathrm{~mol} \%\left(\sim 200 \mathrm{~mJ} / \mathrm{m}^{2}\right)$. The stressstrain curves (Figure 5.b and 5.c) show that as R increases, the maximum debonding stress and critical strain decrease significantly. Consequently, it is clear that changing the hydrogel network 
architecture, such as changing the length of the chains between crosslinks, could lead to a change in the adhesion energy by almost one order of magnitude. Additionally, $W_{a}$ remains nearly constant as the cationic molar concentration increases from $10 \%$ to $20 \%$.

(a)

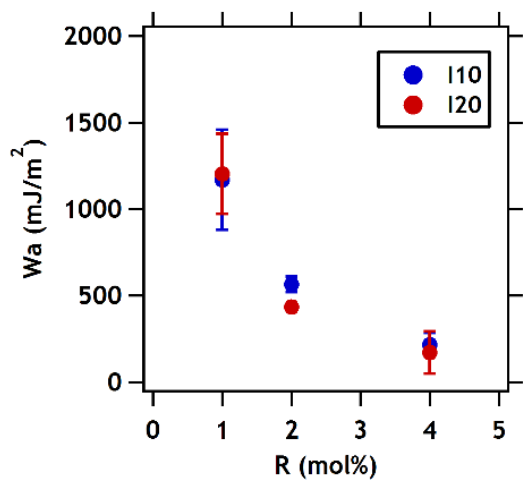

(b)

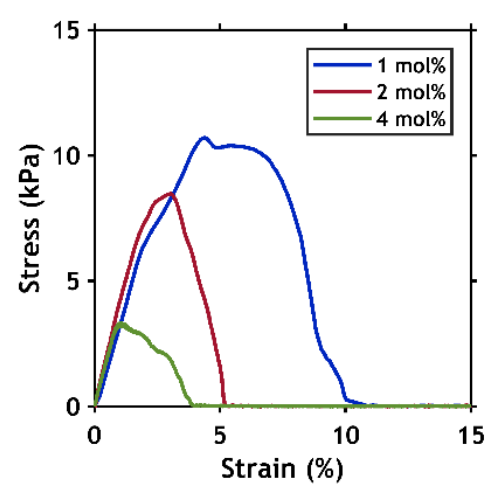

(c)

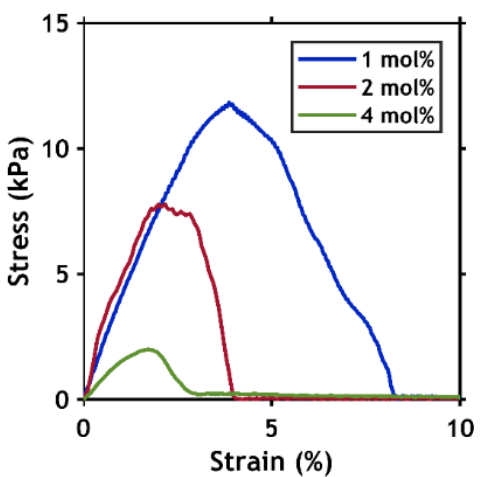

Figure 5. (a) Adhesion energy as a function of R for I10 and I20 hydrogels. Representative stressstrain tack debonding curves of the first contact for I10 (b) and I20 (c) hydrogels with different values of $R$ at a contact time of $1 \mathrm{~s}$ and $\mathrm{V}_{\mathrm{deb}}=0.1 \mathrm{~mm} / \mathrm{s}$.

The effect of $\mathrm{R}$ on $W_{a}$ was also measured at different debonding rates (Figure $\mathrm{S} 4$ ). $W_{a}$ always decreased with the increasing hydrogel crosslinks density regardless of the debonding rate of the test $(0.001 \mathrm{~mm} / \mathrm{s}$ to $1 \mathrm{~mm} / \mathrm{s})$. Moreover, this study probed the boundaries of sensitivity of our methodology. At high degree of crosslinks (R4) and low speeds $(0.01$ and $0.001 \mathrm{~mm} / \mathrm{s})$, the load cell just measured noise (Figure S5.a). On the contrary, a maximum adhesion energy is observed at low degree of crosslinks (R1) and high debonding rate $(1 \mathrm{~mm} / \mathrm{s})$, suggesting that the test mainly measures the toughness of the gel and not $W_{a}$, since the failure mode is cohesive (within the macroscopic cationic hydrogel) and not adhesive (Figure S5.b). 
Effect of the environment: $p H$ effect on $W_{a}$

The molecular electrostatic interactions between the hydrogel and the thin film were tuned by changing the $\mathrm{pH}$ of the tack test medium, since the charge density of the PAA film depends on this variable while the poly(MAETAC-co-AAm) macroscopic hydrogel is permanently charged regardless of the $\mathrm{pH}$. Therefore, the charge density at the surface of the PAA thin film will be maximum around $\mathrm{pH} 9$, when all carboxylic groups are ionized, while in acidic conditions $(\mathrm{pH}<$ 3) there will be no charge at the surface of the film, and consequently no macroscopic adhesion by electrostatic interactions should be observed.

(a)

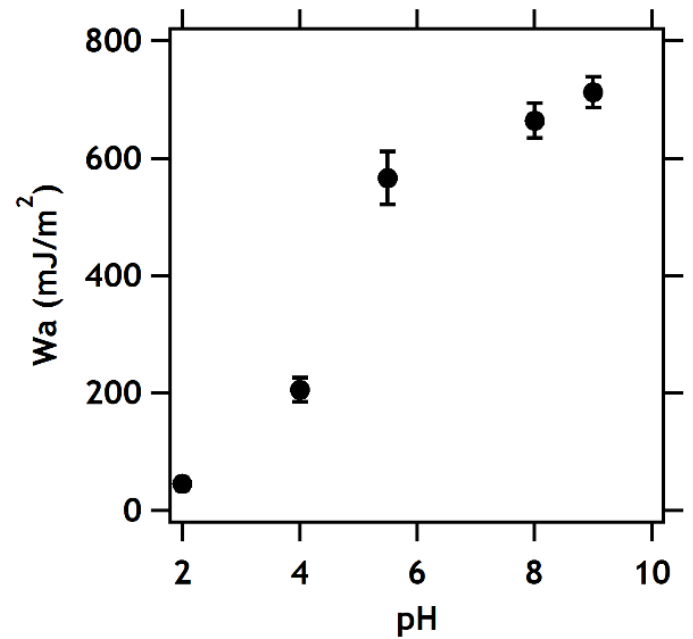

(b)

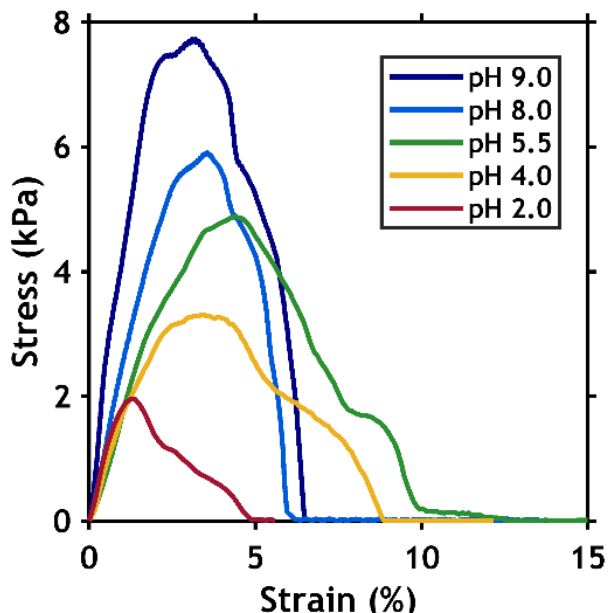

Figure 6. (a) Variation of the adhesion energy as a function of $\mathrm{pH}$ for I10-R2 on the PAA thin film (dry thickness of $150 \mathrm{~nm}$ ) in water at different $\mathrm{pH}$. Contact time $=1 \mathrm{~s}$ and $\mathrm{V}_{\mathrm{deb}}=0.1 \mathrm{~mm} / \mathrm{s}$. (b) Corresponding stress-strain tack debonding curves.

The bulk hydrogel I10-R2 was used for the adhesion tests at different $\mathrm{pH}$ values $(2.0,4.0,5.5$, 8.0 and 9.0). The hydrogels were kept in Milli-Q water until they reached swelling equilibrium. Afterwards, adhesion tests were done at each specific $\mathrm{pH}$ at a contact time of 1 second and a 
debonding rate of $0.1 \mathrm{~mm} / \mathrm{s}$. It should be noted that special care was taken when testing the samples in basic conditions $(\mathrm{pH}>8)$, because when the poly(MAETAC-co-AAm) hydrogels are left under basic conditions for too long $(>1 \mathrm{~h})$, the amide group $\left(-\mathrm{CONH}_{2}\right)$ of acrylamide are prone to hydrolysis into carboxyl groups (-COOH). This will in turn decrease the cationicity of the hydrogel with increasing amount of negative charges, ${ }^{37}$ and will lead consequently to a progressive loss of adhesion energy with the negatively charged thin film as attractive electrostatic forces will decrease. Each hydrogel sample was used for only one experiment at each $\mathrm{pH}$. Three replicates were done for each experiment.

The adhesion energy and maximum debonding force between the I10-R2 hydrogel and PAA thin films was found to increase with $\mathrm{pH}$ (Figure 6.a) reaching a maximum at around $\mathrm{pH} 8-9$. Moreover, the silica on which the PAA hydrogel thin film is grafted, is degraded in highly basic medium, typically above $\mathrm{pH} 9$. By increasing the $\mathrm{pH}$ from 2 to 9 , the maximum stress increased also by a factor of 4 (from $2 \mathrm{kPa}$ to $8 \mathrm{kPa}$, respectively). This simply occurred because more force is needed to separate the two surfaces when more interactions are formed (Figure 6.b).

\section{DISCUSSION}

\subsection{Effect of charge distribution at the interface}

In Section 3, we showed that the content of MAETAC seemed to have no effect on the adhesive properties, at least in the range investigated. These results suggest two things; 1) that the areal density of negative charges controls the adhesion energy and 2) that the density of positive charges on the macroscopic hydrogel side, available at the interface may be in excess. This somewhat surprising result may be rationalized by the deformability of the macroscopic gel allowing positive 
charges to migrate to the interface ${ }^{1}$. Therefore, assuming that the areal density of negative charges controls the number of electrostatic bonds formed at the interface and hence the adhesion properties between the gels, the zeta potential $(\zeta)$ of PAA thin films at different $\mathrm{pH}$ is an important parameter to take into account.

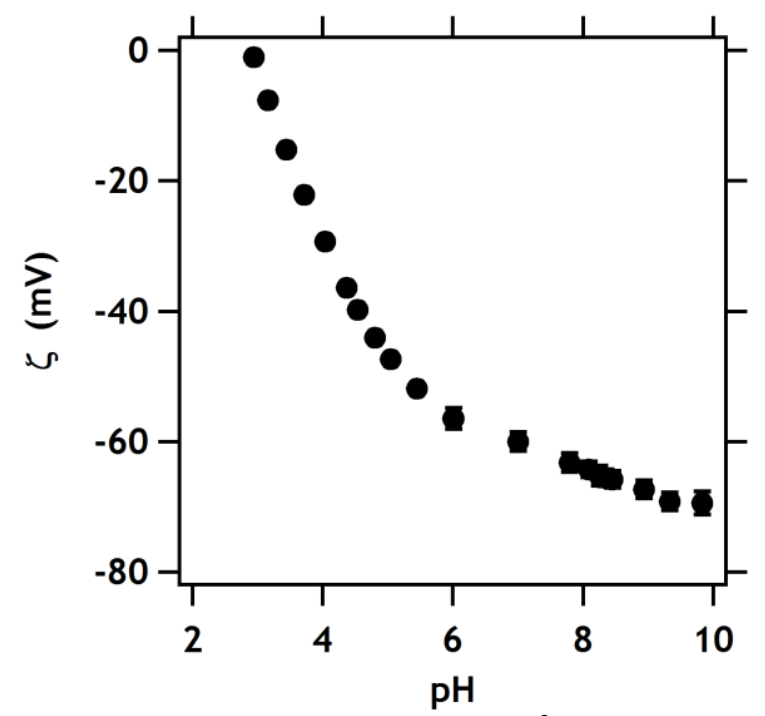

Figure 7. Apparent zeta potential of $\mathrm{PAA}$ thin film in $10^{-3} \mathrm{M} \mathrm{KCl}$ as a function of $\mathrm{pH}$.

Figure 7 shows a representative curve of the streaming potential measurements conducted on PAA thin films as a function of $\mathrm{pH}$. The non-dissociated state is achieved at $\mathrm{pH} 3$ based on the $\mathrm{pH}$ in which $\zeta$ is zero. The increase of negative zeta potential with $\mathrm{pH}$ is due to the increasing dissociation of acidic surface groups. Moreover, $\zeta$ reaches a plateau at $-70 \mathrm{mV}$ when reaching a complete dissociation of acidic functional groups at $\mathrm{pH} \geq 8$. Furthermore, the charge distribution at the interface between the poly(MAETAC-co-AAm) hydrogel and the PAA hydrogel thin film

${ }^{1}$ Although such experiments were not carried out, it is possible that for a lower applied pressure during the contact stage $(\ll 3 \mathrm{kPa})$ or for a higher modulus gel, the density of positive charges available for interactions with the PAA hydrogel thin film will be reduced and that at some point the linear relation of Figure 8 will not hold. 
corresponds to the number of dissociated $\mathrm{COOH}$ groups $\left(\mathrm{nCOO}^{-}\right)$at the very surface of the thin film. Based on the GCSG model, the $\mathrm{nCOO}^{-}$per unit area can be calculated as follows ${ }^{23}$

$$
\mathrm{nCOO}^{-}=\alpha N_{a}
$$

where $\left(N_{a}\right)$ is the number of acidic groups capable of dissociating per unit area and $(\alpha)$ is the degree of dissociation of PAA functional groups.

The data of the zeta-potential $(\zeta)$ can be used to estimate the degree of dissociation $(\alpha)$ of PAA functional groups on the surface based on the GSCG model as follows ${ }^{38}$

$$
\alpha=\frac{1}{1+e\left(-2.3\left(\mathrm{pH}-p K_{a}\right)-\frac{\mathrm{F}}{\mathrm{R}} \frac{\zeta}{T}\right)}
$$

with $\mathrm{F}$ the Faraday constant, $\mathrm{R}$ the gas constant, $\mathrm{T}$ the temperature, $K_{a}$ the dissociation constant of acrylic acid units; $p K_{a}=f(\mathrm{pH})$ being calculated as follows ${ }^{23,38}$

$$
p K_{a}=\mathrm{pH}+0.4343\left\{\frac{F \zeta}{R T}+\ln \left[\frac{\sinh \left(-\frac{F \zeta_{\text {plateau }}}{2 R T}\right)}{\sinh \left(-\frac{F \zeta}{2 R T}\right)}-1\right]\right\}
$$

where $\zeta_{\text {plateau }}$ is the zeta-potential value when all dissociable groups are dissociated $(\alpha \sim 1)$, which for the PAA thin films is $\left.\zeta_{\text {plateau }}=\zeta(\mathrm{pH}>8) \mid \alpha=1\right)=-70 \mathrm{mV}$. Finally, the number of acidic groups capable of dissociating per unit area is given by the Grahame equation 39,40

$$
N_{a}=\frac{1}{e_{0}} \sqrt{8 \varepsilon_{r} \varepsilon_{0} c^{\infty} R T} \sinh \left[-\frac{F \zeta_{\text {plateau }}}{2 R T}\right]
$$

where, $e_{0}$ is the charge of an electron $\left(1.6 \times 10^{-19} \mathrm{C}\right), \varepsilon_{r}$ is the dielectric constant of the measuring fluid (80 for pure water), $\varepsilon_{0}$ is the vacuum permittivity $\left(8.85 \times 10^{-12} \mathrm{C}^{2} \mathrm{~J}^{-1} \mathrm{~m}^{-1}\right)$, and $c^{\infty}$ is the ions concentration of the $\mathrm{KCl}$ solution $\left(1 \mathrm{~mol} / \mathrm{m}^{3}\right)$. The calculated constant number of acidic groups capable of dissociating $\left(N_{a}\right)$ is therefore $6.8 \times 10^{-3} \mathrm{C} / \mathrm{m}^{2}$, which is equivalent to $4.23 \times 10^{16}$ $n \mathrm{COO}^{-} / \mathrm{m}^{2}=0.0423 n \mathrm{COO}^{-} / \mathrm{nm}^{2}$. 
Combining the streaming potential experiments with the adhesion experiments (Figure 8), we are now able to quantitatively correlate the energy of adhesion $\left(W_{a}\right)$, to the $\mathrm{pH}$ of the medium by using the number of dissociated groups per unit area $\left(n \mathrm{COO}^{-} / \mathrm{nm}^{2}\right)$. This correlation suggests that the charge density at the interface can indeed be modified by adjusting the $\mathrm{pH}$ of the medium and that $W_{a}$ strongly depends on this charge density. Quantitatively, the adhesion energy increased linearly from $200 \mathrm{~mJ} / \mathrm{m}^{2}$ at a charge density of $1.4 \times 10^{-2} n \mathrm{COO}^{-} / \mathrm{nm}^{2}$ to $800 \mathrm{~mJ} / \mathrm{m}^{2}$ with a charge density around $4 \times 10^{-2} n \mathrm{COO}^{-} / \mathrm{nm}^{2}$.

(a)

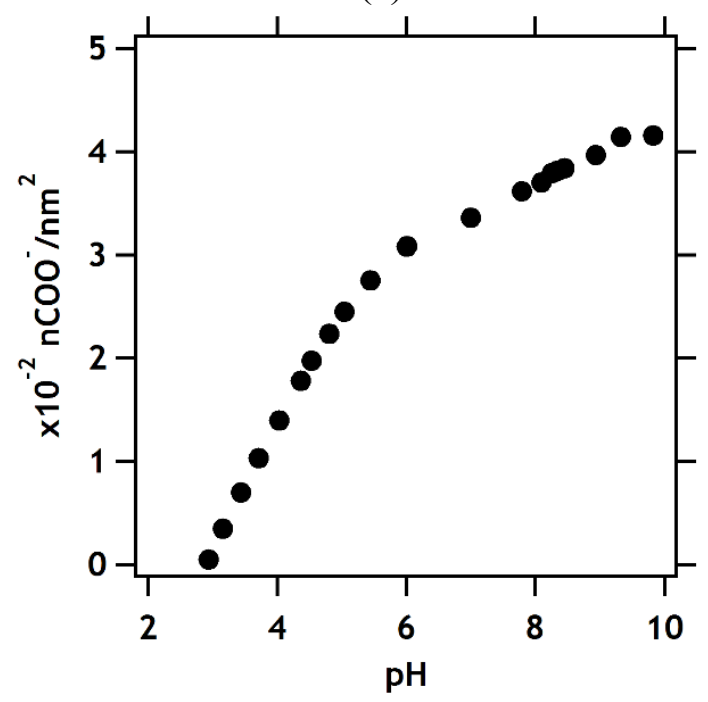

(b)

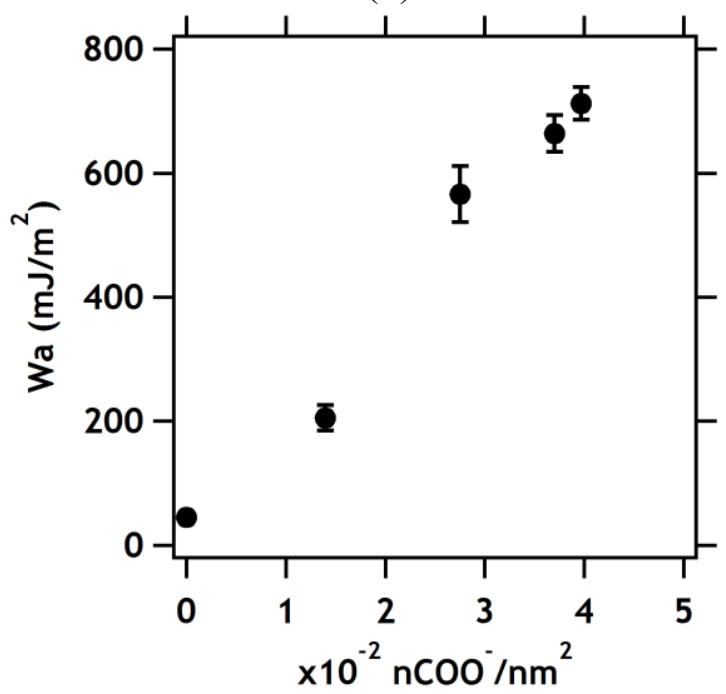

Figure 8. (a) Variation of the number of dissociated groups per unit area as function of the $\mathrm{pH}$ estimated from streaming potential measurements; (b) Adhesion energy of I10-R2 on PAA hydrogel thin films as measured by the tack test as a function of the approximate number of dissociated groups per unit area at the interface of the hydrogel thin film. Contact time $=1 \mathrm{~s}$ and $\mathrm{V}_{\mathrm{deb}}=0.1 \mathrm{~mm} / \mathrm{s}$.

\subsection{Chaudhury's model for kinetic bond scission applied to underwater adherence}

Chaudhury proposed a model to predict the variation of adhesion energy from kinetic bond theory adapting the work of Evans on single molecules to the case of non dissipative elastomers. ${ }^{26}$ 
In his model, he assumes that the macroscopic rate dependence of the adhesion energy is due to the rate dependence of the scission of a weak bond attached to a polymeric chain. He assumed that tethered chains composed by strong bonds and with a terminal weak bond attached to a network across the interface, would be stretched before this latter bond fails. Essentially, since the probability of failure of the weak bond increases with force, the time of failure increases with the logarithm of the pulling rate. According to his model, the interfacial fracture energy $\left(W_{a}\right)$ for relatively fast debonding rates can be described as follows:

$$
W_{a}=\left(\frac{\Sigma_{i}}{2 k_{s}}\right)\left[\left(\frac{k_{B} T}{\lambda}\right) \ln \left(\frac{k_{s} V \lambda \tau_{-}}{n k_{B} T}\right)\right]^{2}
$$

where $\Sigma_{i}$ is the areal density of weak bonds. $\lambda$ is the activation length of the bond, which we assume to be $0.1 \mathrm{~nm}$, that is, slightly larger than typical covalent bond lengths ${ }^{40} . k_{s}$ is the linear spring constant of the polymer chain which we assume inversely proportional to the number of monomers in the chain $\left(N_{c}\right) \cdot \tau_{-}$is the characteristic time of bond dissociation, $k_{B}$ is the Boltzmann's constant and $n$ is the number of weak bonds in the polymer chain (one in our case). $V$ in Chaudhury's model is the velocity at which the chain is being stretched. Since this quantity is not directly measureable, we will assume that $V$ is proportional to $V_{d e b}$.

We now adapt this model to our system (Figure 9): the adhesion is due to weak bonds attached to a flexible chain composed of strong bonds that cannot break and it takes place in immersed conditions where Van der Waals forces are small. In this model, it is possible to assume that only one weak bond is present in a polymer chain and that only the deformation of the chains of the cationic hydrogel contribute to $W_{a}$. We assume that there is no contribution from the deformation of the hydrogel thin film since the equilibrium swelling that we measure is very low, indicating a high crosslink density. Additionally, we assume that there is an excess of polycations available 
on the gel chains to attach to a negatively charged site so that $\Sigma_{i}$ is already known from the

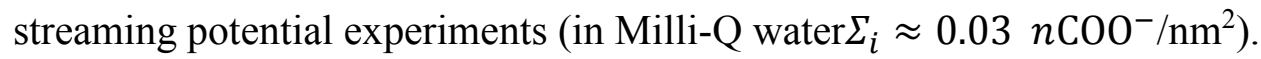

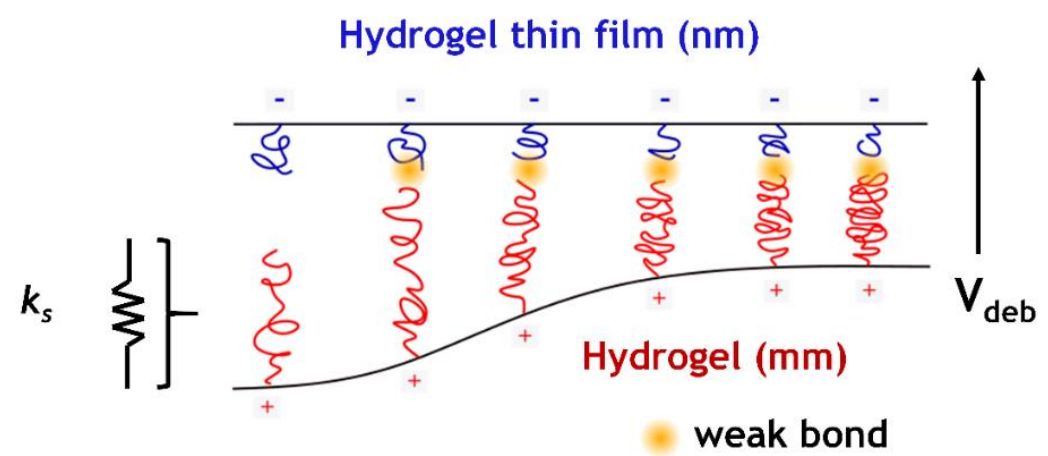

Figure 9. Schematic representation of the crack tip region between the positively charged hydrogel of poly(MAETAC-co-AAm) (in red) and the negatively charged hydrogel thin film of PAA (in blue). The yellow circles represent the weak bond (electrostatic interaction).

\subsection{Prediction of the effect of debonding velocity}

Based on the experimental value of the adhesion energy as a function of the detachment rate $V_{d e b}$ (which is assumed to be proportional to the rate at which the chain is pulled $V$ ), it is possible to plot $W_{a}^{1 / 2}\left(k_{B} T / \lambda\right)^{-1}$ as a function of $\ln V_{d e b}$ for the gel I10-R2 (Figure 10). The slope and intercept of this plot give an estimate of the spring constant $k_{s}$ of the polymer chain and of the dissociation time $\tau_{-}$of the electrostatic bond. With the value of $\Sigma_{i}$ obtained in section 4.1 and the value of $N_{c}$ of Table 1 , the values of $k_{s}$ and $\tau_{-}$are, thus, estimated to be $1.1 \mathrm{mN} / \mathrm{m}$ and $0.12 \mathrm{~s}$, respectively. 


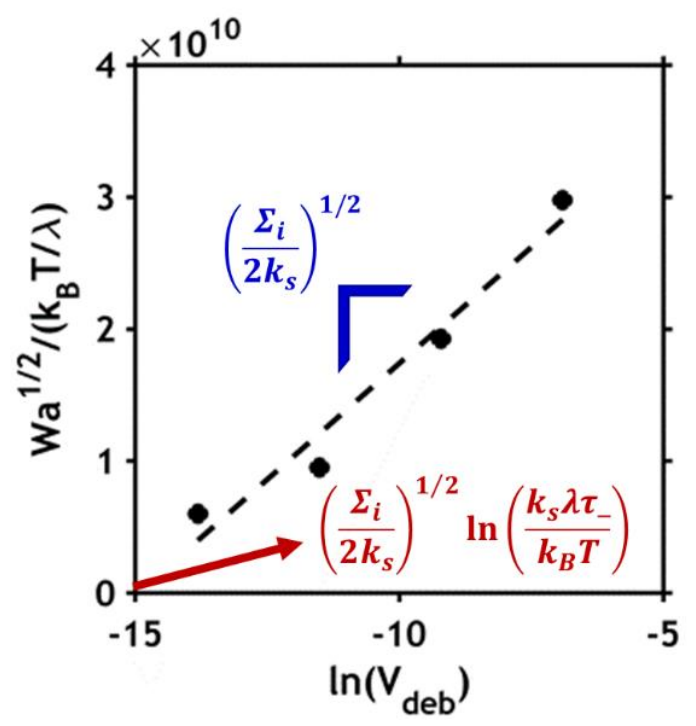

Figure 10. $W_{a}^{1 / 2}\left(k_{B} T / \lambda\right)^{-1}$ as function of $\ln V_{d e b}$ for the I10-R2 gel against the PAA thin hydrogel film. Black symbols are the experimental data (contact time 1s) and the dashed line is the best fit to Chaudhury's model discussed in the text. The red line points the intercept in the yaxis.

The calculated value of $k_{s}$ is lower than the spring constant of a polymeric chain in its enthalpic limit reflecting the fact that the electrostatic bond can stretch the polymer chain almost until its maximum length. Note that the stiffness of the polymer chain for a strong bond $\left(k_{s-e}\right)$ was defined by Chaudhury et al. as ${ }^{41}$

$$
k_{s-e}=\frac{2 N_{c}\left(U_{c} / N_{a v}\right)}{\left(2 N_{c} \cos \left(\frac{\theta}{2}\right) b\right)^{2}}
$$

where $U_{c}$ is the bond energy of the covalent bond $(400 \mathrm{~kJ} / \mathrm{mol}), N_{a v}$ is the Avogadro's number, $b$ is the bond length $(0.154 \mathrm{~nm})$ and $\cos \left(\frac{\theta}{2}\right)$ equal to 0.81 . Using the value of Table 1 for $N_{c}$ (which is 40 units for I10-R2) we can calculate with equation 12 a $k_{s-e}=0.53 \mathrm{~N} / \mathrm{m}$. This spring constant is two orders of magnitude higher than the value obtained by fitting the data of 
Figure 10 consistent with the relatively weak bond that break before the chain ca come close to its full extension. Furthermore, according to Eyring, the natural relaxation time of a chemical bond is

$$
\tau_{-}=\frac{h}{k_{B} T} \exp \left(\frac{E_{a}}{k_{B} T}\right)
$$

where $h$ is the Plank's constant. Therefore, the bond activation energy for an electrostatic interaction is calculated to be $27.3 k_{B} T(66.5 \mathrm{~kJ} / \mathrm{mol})$ which is lower than a covalent bond and in the same magnitude of $6 k_{B} T$ as measured by Spruijt et al. ${ }^{10}$ Moreover, according to Hui ${ }^{41}$ if the dimensionless parameter $\beta$ defined as

$$
\beta=\frac{k_{B} T}{V_{d e b} \tau_{-} k_{s} \lambda}
$$

is lower than 1 , this means that the energy release rate for crack growth corresponds to high crack speeds or long relaxation times. At high crack speeds only chains close to the crack tip are broken as oppositely to slow crack speeds where chains are broken everywhere except those close to the crack tip. For our case $\beta$ is equal to $3.22 \times 10^{-3}$ at a detachment rate of $0.1 \mathrm{~mm} / \mathrm{s}$, independent on the $\Sigma_{i}$, meaning that regardless of the interfacial charge density, this system will always fail in the high crack speed regime.

\subsection{Prediction of the adhesion energy from the degree of crosslinking of the hydrogel.}

In section 3, in addition we showed that the crosslinker concentration of positively charged hydrogels considerably affected the adhesion energy $W_{a}$ when measured against the same negatively charged surface. Since Chaudhury's model assumes that polymer chains are linear springs with constant $k_{s}$, we propose to use this model to predict the adhesion energy as a function of the length of the polymer chain $\left(N_{c}\right)$ since $k_{s}=C / N_{c}$, where $C$ is the coefficient that relates the spring constant of the polymer chain as found in section 4.3 for the I10-R2 hydrogel 
$\left(k_{s}=1.1 \mathrm{mN} / \mathrm{m}, N_{c}=40\right.$ units). Therefore, the coefficient $C$ is calculated to be 0.045 . Finally, $W_{a}$ will be a function of $N_{c}$ as follows

$$
W_{a}=k_{1} N_{c}\left[\ln \left(\frac{k_{2}}{N_{c}}\right)\right]^{2}
$$

where $k_{1}$ will be function of the interfacial charge density $\Sigma_{i}$ and $k_{2}$ will be a function of the velocity and both coefficients can be calculated as follows

$$
k_{1}=\Sigma_{i}\left[\frac{1}{2 C}\left(\frac{k_{B} T}{\lambda}\right)^{2}\right]=5.3 \times 10^{-4} \frac{\mathrm{J}}{\mathrm{m}^{2}}, \quad k_{2}=V_{d e b}\left(\frac{C \tau_{-}}{k_{B} T}\right)=1.2 \times 10^{4}
$$

The data of Figure 5 can now be replotted in Figure 11 as a function of $N_{c}$, and compared with the prediction of $W_{a}$ based on Chaudhury's model. $W_{a}$ was calculated for polymer chains with $0<$ $N_{c}<200$ with $k_{1}$ and $k_{2}$ as calculated previously. $N_{c}$ was directly taken from Table 1 for the experimental values of $W_{a}$. Remarkably, the model is able to predict the tendency of the experimental data, which is to increase macroscopic underwater adhesion, as does the length of the chains between crosslinks. At higher values of $N_{c}$ the model predicts reasonably well the adhesion energy for two orders of magnitude of debonding rates (Figure S7). In contrast, at low values of $N_{c}$, the discrepancy between the experimental data and the model could be due to the fact that the model is based on molecular aspects only and may still need to take into account variation of bulk dissipative mechanisms.

It should be noted that Chaudhury's model predicts a local maximum of $W_{a}$ of approximately 4 $\mathrm{J} / \mathrm{m}^{2}$ for $N_{c}=1440$ (Figure S8). However, it is not experimentally feasible to prepare a hydrogel with this architecture since no elastic and tough hydrogel will be obtained with a $0.04 \mathrm{~mol} \%$ of crosslinker concentration (i.e. the theoretical concentration to obtain a polymer chain of $\sim 1440$ monomer units). 
(a)

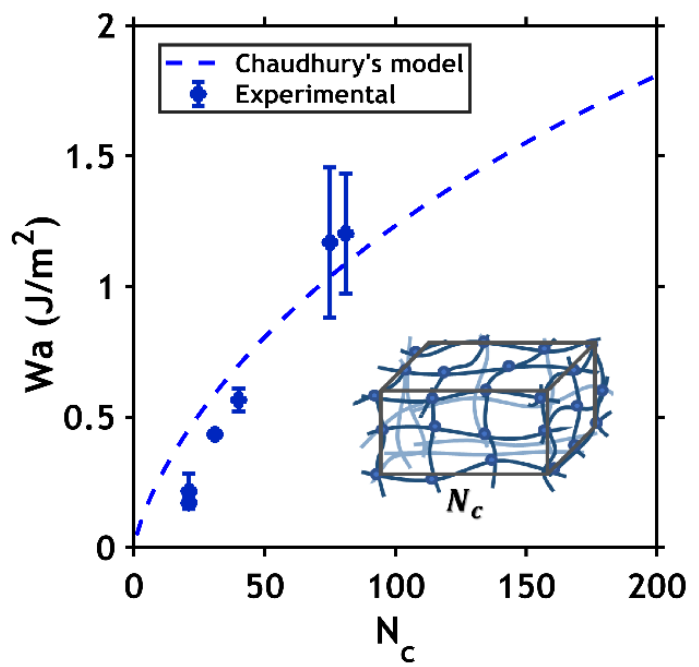

(b)

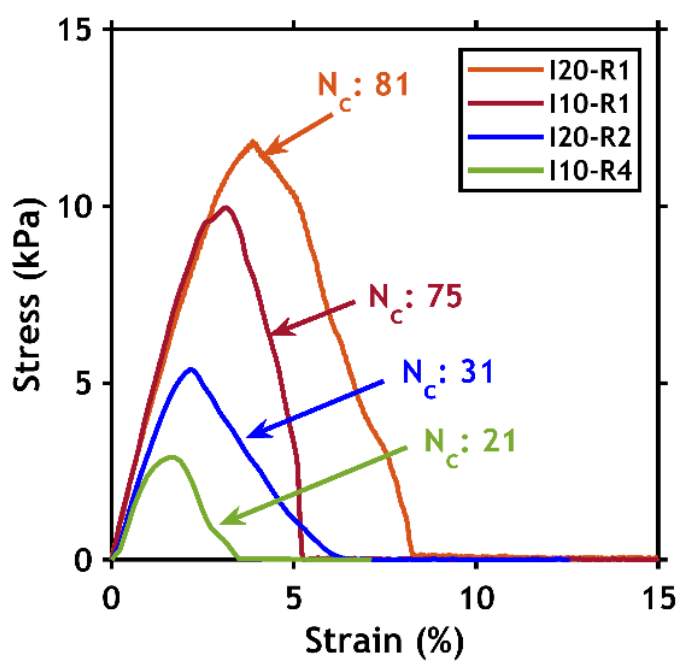

Figure 11. (a) Adhesion energy $W_{a}$ as function of the number of monomers in the polymer chain of the poly(MAETAC-co-AAm) hydrogel $N_{c}$. Points are experimental data and the dashed line is the prediction of Chaudhury's model. (b) Representative stress-strain tack debonding curves of the first contact for different number of monomers between crosslinks, $N_{c}$ of poly(MAETAC-coAAm) hydrogels.

\section{CONCLUSIONS}

Macroscopic underwater adhesion between oppositely charged polyelectrolytes is a complex multi-parameter problem, and the effect of some of these parameters has been highlighted in this study. The model system that we used (elastic positively charged hydrogel and negatively charged surface) emphasizes the role played by molecular interactions, specifically electrostatic interactions, on the strength of macroscopic adhesion of hydrogels underwater. We investigated the contribution of the elastic properties of the hydrogel and of the charge density at the interface and the main conclusions are the following: For a fixed gel and debonding conditions we find that the macroscopic adhesion depends linearly on the density of bonding sites at the interface. For a 
fixed density of binding sites and a fixed gel, the macroscopic underwater adhesion increases weakly with contact time (in stark contrast with the case of H-bonds) but strongly with debonding rate, in semi-quantitative agreement with Chaudhury's model for kinetic bond scission. Finally and importantly for fixed bonding and debonding conditions and fixed charge density, $W_{a}$ increases with the inverse of the elastic modulus and can be modelled semi-quantitatively. It was found on the hydrogel side that underwater adhesion energy depends strongly on the rigidity of the hydrogels (hydrogel shear moduli). When the shear modulus increases the macroscopic adherence decreases in an analogous way to what is predicted for fracture of simple soft networks in gels or elastomers. ${ }^{25}$

The underwater macroscopic adherence resulting from electrostatic interactions of an elastic gel with shear modulus between $30 \mathrm{kPa}$ and $150 \mathrm{kPa}\left(20<N_{c}<70\right)$ can be well predicted by knowing the charge density of the interface. However, this prediction works well only at debonding rates between $10 \mu \mathrm{m} / \mathrm{s}$ and $100 \mu \mathrm{m} / \mathrm{s}$. outside this limits, the model will requires additional information regarding the kinetics behavior of the interaction at lower and faster debonding rates.

\section{ASSOCIATED CONTENT}

Supporting Information. Photographs of a poly(MAETAC-co-AAm) hydrogel and a PAA hydrogel thin film. (Figure S1); ${ }^{1} \mathrm{H}$ NMR spectrum of ene-functionalized PAA. (Figure S2); Examples of the stress-strain tack debonding curves for adhesion energy results of the poly(MAETAC-co-AAm) hydrogels and the PAA thin film (with dry thickness of $150 \mathrm{~nm}$ ) as function of number of contacts. (Figure S3); Adhesion energy as a function of crosslinkers concentration for I10 at different debonding rates. (Figure S4); Stress-strain curves for I10-R4 at $0.001 \mathrm{~mm} / \mathrm{s}$ and for $\mathrm{I} 10-\mathrm{R} 1$ at $1 \mathrm{~mm} / \mathrm{s}$. (Figure S5); Adhesion energy and the degree of dissociation 
$\alpha$ of PAA hydrogel thin films as function of $\mathrm{pH}$ of the medium. (Figure S6); Comparison of the Chaudhury model and experimental values of $W_{a}$ at three different debonding rates (Figure S7); Adhesion energy $W_{a}$ as predicted by the Chaudhury model using higher values of $N_{c}$. Stress-strain tack debonding curve I10-R002 hydrogel (Figure S8).

\section{AUTHOR INFORMATION}

\section{Corresponding Author}

*Costantino Creton. costantino.creton@espci.fr

\section{Funding Sources}

This work has received funding from the European Union's Horizon 2020 research and innovation programme under the Marie Skłodowska-Curie grant agreement No. 642861 European training Network BiosmartTrainee.

\section{REFERENCES}

(1) Stewart, R. J.; Ransom, T. C.; Hlady, V. Natural Underwater Adhesives. J. Polym. Sci. Part B Polym. Phys. 2011, 49 (11), 757-771.

(2) Bhagat, V.; Becker, M. L. Degradable Adhesives for Surgery and Tissue Engineering. Biomacromolecules 2017, 18 (10), 3009-3039.

(3) Mehdizadeh, M.; Yang, J. Design Strategies and Applications of Tissue Bioadhesives. Macromol. Biosci. 2013, 13 (3), 271-288.

(4) Hofman, A. H.; van Hees, I. A.; Yang, J.; Kamperman, M. Bioinspired Underwater Adhesives by Using the Supramolecular Toolbox. Adv. Mater. 2018, 1704640, 1-38. 
(5) Li, J.; Celiz, A. D.; Yang, J.; Yang, Q.; Wamala, I.; Whyte, W.; Seo, B. R.; Vasilyev, N. V.; Vlassak, J. J.; Suo, Z.; et al. Tough Adhesives for Diverse Wet Surfaces. Science (80-. ). 2017,357 (6349), 378-381.

(6) Spina, R. La; Tomlinson, M. R.; Ruiz-pørez, L.; Chiche, A.; Langridge, S.; Geoghegan, M. Controlling Network - Brush Interactions to Achieve Switchable Adhesion **. Angew. Chemie Int. Ed. 2007, 46, 6460-6463.

(7) Nyarko, A.; Barton, H.; Dhinojwala, A. Scaling down for a Broader Understanding of Underwater Adhesives - a Case for the Caulobacter Crescentus Holdfast. Soft Matter 2016, 12 (45), 9132-9141.

(8) Alfhaid, L.; Spina, R. La; Tomlinson, M. R.; Hall, A. R.; Seddon, D.; Williams, N. H.; Cousin, F.; Gorb, S.; Geoghegan, M. Adhesion between Oppositely Charged Polyelectrolytes. J. Adhes. 2016, 94 (1), 58-76.

(9) Dobrynin, A. V.; Rubinstein, M. Theory of Polyelectrolytes in Solutions and at Surfaces. Prog. Polym. Sci. 2005, 30 (11), 1049-1118.

(10) Spruijt, E.; Van Den Berg, S. A.; Cohen Stuart, M. A.; Van Der Gucht, J. Direct Measurement of the Strength of Single Ionic Bonds between Hydrated Charges. ACS Nano 2012, 6 (6), 5297-5303.

(11) Tagliazucchi, M.; de la Cruz, M. O.; Szleifer, I. Self-Organization of Grafted Polyelectrolyte Layers via the Coupling of Chemical Equilibrium and Physical Interactions. Proc. Natl. Acad. Sci. 2010, 107 (12), 5300-5305.

(12) Shull, K. R. Contact Mechanics and the Adhesion of Soft Solids. Mater. Sci. Eng. R Reports $\mathbf{2 0 0 2}, 36(1), 1-45$.

(13) Kobayashi, M.; Terada, M.; Takahara, A. Reversible Adhesive-Free Nanoscale Adhesion Utilizing Oppositely Charged Polyelectrolyte Brushes. Soft Matter 2011, 7, 5717-5722.

(14) Drechsler, A.; Synytska, A.; Uhlmann, P.; Stamm, M.; Kremer, F. Tuning the Adhesion of Silica Microparticles to a Poly ( 2-Vinyl Pyridine ) Brush : An AFM Force Measurement Study. Langmuir 2012, 28, 15555-15565. 
(15) Spruijt, E.; Stuart, M. a C.; Van Der Gucht, J. Dynamic Force Spectroscopy of Oppositely Charged Polyelectrolyte Brushes. Macromolecules 2010, 43, 1543-1550.

(16) Wei, W.; Yu, J.; Gebbie, M. A.; Tan, Y.; Martinez Rodriguez, N. R.; Israelachvili, J. N.; Waite, J. H. Bridging Adhesion of Mussel-Inspired Peptides: Role of Charge, Chain Length, and Surface Type. Langmuir 2015, 31 (3), 1105-1112.

(17) Dunlop, I. E.; Briscoe, W. H.; Titmuss, S.; Jacobs, R. M. J.; Osborne, V. L.; Edmondson, S.; Huck, W. T. S.; Klein, J. Direct Measurement of Normal and Shear Forces between Surface-Grown Polyelectrolyte Layers. J. Phys. Chem. B 2009, 113 (12), 3947-3956.

(18) Hayashi, S.; Abe, T.; Higashi, N.; Niwa, M.; Kurihara, K. Polyelectrolyte Brush Layers Studied by Surface Forces Measurement: Dependence on PH and Salt Concentrations and Scaling. Langmuir 2002, 18 (10), 3932-3944.

(19) Rose, S.; Prevoteau, A.; Elzière, P.; Hourdet, D.; Marcellan, A.; Leibler, L. Nanoparticle Solutions as Adhesives for Gels and Biological Tissues. Nature 2014, 505 (7483), 382-385.

(20) Sudre, G.; Olanier, L.; Tran, Y.; Hourdet, D.; Creton, C. Reversible Adhesion between a Hydrogel and a Polymer Brush. Soft Matter 2012, 8, 8184-8193.

(21) Macron, J.; Bresson, B.; Tran, Y.; Hourdet, D.; Creton, C. Equilibrium and Out-ofEquilibrium Adherence of Hydrogels against Polymer Brushes. Macromolecules 2018, 51 (19), 7556-7566.

(22) Werner, G.; Körber, H.; Zimmermann, R.; Dukhin, S.; Jacobasch, H. J. Extended Electrokinetic Characterization of Flat Solid Surfaces. J. Colloid Interface Sci. 1998, 208 (1), 329-346.

(23) Hunter, R. J. Zeta Potential in Colloid Science: Principles and Applications; 1981.

(24) Lake, G. J.; Thomas, A. G. The Strength of Highly Elastic Materials. Proc. R. Soc. A Math. Phys. Eng. Sci. 1967, 300 (1460), 108-119.

(25) Ciccotti, M.; Creton, C. Fracture and Adhesion of Soft Materials : A Review. Reports Prog. Phys. 2016, 79, 046601. 
(26) Chaudhury, M. K. Rate-Dependent Fracture at Adhesive Interface. J. Phys. Chem. B 1999, 103, 6562-6566.

(27) Merkel, R.; Nassoy, P.; Leung, A.; Ritchie, K.; Evans, E. Energy Landscapes of ReceptorLigand Bonds Explored with Dynamic Force Spectroscopy. Nature 1999, 397 (6714), 5053.

(28) Evans, E. A.; Ritchie, K. Strength of a Weak Bond Connecting Flexible Polymer Chains. Biophys. J. 1999, 76 (5), 2439-2447.

(29) Chollet, B.; D’Eramo, L.; Martwong, E.; Li, M.; Macron, J.; Mai, T. Q.; Tabeling, P.; Tran, Y. Tailoring Patterns of Surface-Attached Multiresponsive Polymer Networks. ACS Appl. Mater. Interfaces 2016, 8 (37), 24870-24879.

(30) Li, M.; Bresson, B.; Cousin, F.; Fretigny, C.; Tran, Y. Submicrometric Films of SurfaceAttached Polymer Network with Temperature-Responsive Properties. Langmuir 2015, 31, 11516-11524.

(31) Miquelard-Garnier, G.; Demeures, S.; Creton, C.; Hourdet, D. Synthesis and Rheological Behavior of New Hydrophobically Modified Hydrogels with Tunable Properties. Macromolecules 2006, 39 (23), 8128-8139.

(32) Rubinstein, M.; Colby, R. H. Polymer Physics, 1 edition.; Oxford University Press, 2003.

(33) Duval, J. F. L.; Küttner, D.; Nitschke, M.; Werner, C.; Zimmermann, R. Interrelations between Charging, Structure and Electrokinetics of Nanometric Polyelectrolyte Films. J. Colloid Interface Sci. 2011, 362 (2), 439-449.

(34) Smoluchowski, M. Handbuch Der Elektrizität Und Magnetismus; Graetz, L., Ed.; Leipzig, 1921.

(35) Obukhov, S. P.; Rubinstein, M.; Colby, R. H. Network Modulus and Superelasticity. Macromolecules 1994, 27 (12), 3191-3198.

(36) Chollet, B.; Li, M.; Martwong, E.; Bresson, B.; Fretigny, C. Multiscale Surface-Attached Hydrogel Thin Films with Tailored Architecture. ACS Appl. Mater. Interfaces 2016, 8, 
$11729-11738$.

(37) Tanaka, T.; Sun, S. T.; Nishio, I.; Swislow, G.; Shah, A. Phase Transitions In Ionic Gels. Phys. Rev. Lett. 1980, 45 (20), 1636-1639.

(38) Jacobasch, H. J. Characterization of Solid Surfaces by Electrokinetic Measurements. Prog. Org. Coatings 1989, 17 (2), 115-133.

(39) Grahame, D. C. Diffuse Double Layer Theory for Electrolytes of Unsymmetrical Valence Types. J. Chem. Phys. 1953, 21 (6), 1054-1060.

(40) Israelachvili, J. N. Intermolecular and Surface Forces, 3 edition.; Academic Press, 2011.

(41) Hui, C. Y.; Tang, T.; Lin, Y. Y.; Chaudhury, M. K. Failure of Elastomeric Polymers Due to Rate Dependent Bond Rupture. Langmuir 2004, 20 (14), 6052-6064. 


\section{Table of Contents Graphic}

\section{Manuscript title:}

From Molecular Electrostatic Interactions and Hydrogel Architecture to Macroscopic Underwater Adherence

\section{List of authors:}

Francisco J. Cedano-Serrano, Ugo Sidoli, Alla Synytska, Yvette Tran, Dominique Hourdet and Costantino Creton.
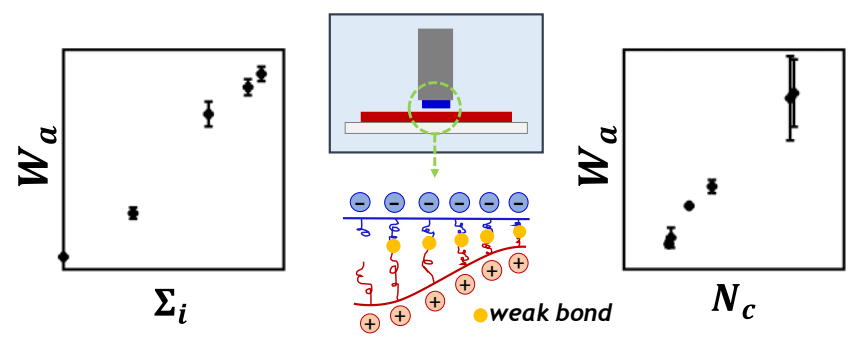